\title{
A Prospective, Randomised, Double-Blind Comparative Study of IV Granisetron Vs Dexamethasone as Antiemesis Prophylaxis in Patients Undergoing Elective Abdominal Laparoscopic Surgery
}

\author{
Dr. Naina P Dalvi ${ }^{1}$, Dr. Sagar Chimalwar ${ }^{2}$
}

\begin{abstract}
A Prospective, Randomised, Double-Blind Comparative Study of IV Granisetron Vs Dexamethasone as Antiemesis Prophylaxis in Patients Undergoing Elective Abdominal Laparoscopic Surgery. Introduction: This prospective, randomised, double blind study compared the efficacy and adverse effects of injection Granisetron and Dexamethasone for prevention of postoperative nausea and vomiting in patients undergoing elective laparoscopic surgery. Methods: Sixty patients of either sex, aged 18-60 years, ASA grade I/II, posted for elective laparoscopic surgery were administered either Granisetron 40 $\mu$ g/kg intravenously, or Dexamethasone $160 \mu \mathrm{g} / \mathrm{kg}$ intravenously just before the induction of Anaesthesia. The efficacy of study medication was assessed in terms of number of episodes of emesis, percentage of emesis free patients, percentage of nausea free patients for 24 hours post operatively. Results: Sixty patients were randomized into group $G(n=30)$ and group $D(n=30)$. Total five patients (16\%) had nausea and one patient $(3.3 \%)$ had vomiting in group G. Whereas five patients (16\%) had nausea and two (6.7\%) had vomiting in group $D$ at first four hours postoperatively. In 4 to 24 hours postoperatively, Granisetron proved to have superior antiemetic effect than Dexamethasone in which three patients (10\%) had nausea and six patients (20\%) had vomiting as compared to none with granisetron. Discussion: The single dose of $160 \mathrm{\mu g} / \mathrm{kg}$ of dexamethasone is economical, without any known adverse effects and is equally effective as granisetron in first 4 hours postoperative but Granisetron $40 \mu \mathrm{g} / \mathrm{kg}$ is more effective in preventing postoperative nausea and vomiting with minimal adverse effect and will prove cost - effective in patients undergoing laparoscopic surgeries.
\end{abstract}

Keywords: Granisetron, Dexamethasone, Antiemesis, Laparoscopic surgery

\section{Introduction}

Post operative nausea and vomiting (PONV) are among the most common adverse events following both inpatient and day care surgery, general, regional or local anaesthesia and opioid analgesia. [1] PONV is a limiting factor (30\% incidence) in the early discharge of ambulatory surgery patients and is a leading cause of development of medical complications, unanticipated hospital admission. It can lead to increased recovery room time, expanded nursing care, increased use of resources, all factors that may increase total health care costs. [2] Among high risk patients, the incidence of PONV can be as frequent as $70 \%$ to $80 \%$. In gynecological laparoscopies, the incidence is $50-80 \%$ while in laparoscopic cholecystectomy, the incidence of PONV is $53 \%-72 \%$. [3]

The aetiology of PONV is multifactorial, involving physiological, pathological and pharmacological factors. It is more common in women than men and in younger patients [1].A number of anti-emetics have been studied for the prevention and treatment of this complication [4] and are grouped according to the type of receptor at which they act, usually as an antagonist like anticholinergic, antihistaminics, Dopamine $\left(\mathrm{D}_{2}\right)$ receptor antagonist, $5 \mathrm{HT}_{3}$ receptor antagonist and corticosteroid. [1]

Selective sertonin type $3\left(5 \mathrm{HT}_{3}\right)$ receptor antagonists are considered a first line therapy because of their efficacy and safety compared with other drugs, currently in use are dolasetron, granisetron and ondansetron. [5] The use of these $5 \mathrm{HT}_{3}$ receptor antagonist has been shown to improve patient satisfaction, decrease recovery and discharge times and reduce unanticipated hospital admissions. $[6,7,8]$

Since 1981, dexamethasone has been reported to be effective in reducing the incidence of emesis in patients undergoing chemotherapy. The antiemetic effect of dexamethasone was reported to be equal to or better than the $5-\mathrm{HT}_{3}$ receptor antagonists, such as ondansetron and granisetron. [4, 9]

We conducted a prospective, randomised, double-blind comparative study to compare the efficacy and adverse effects of injection Granisetron and Dexamethasone for prevention of postoperative nausea and vomiting in patients undergoing elective abdominal laparoscopic surgery like appendicectomy and cholecystectomy, a population that has a high likelihood of experiencing these complications.

\section{Materials And Methods}

After taking approval from the institution's ethics committee, written informed, valid consent was taken from all patients after explaining the study protocol. It was a prospective, randomised, double blind, comparative study.

Sixty patients of either sex, aged 18-60 years, ASA grade I/II, posted for elective abdominal laparoscopic surgery were included in the study.ASA grade III, IV or V, pregnant \& lactating women, patients having systemic disorders 


\section{International Journal of Science and Research (IJSR) \\ ISSN (Online): 2319-7064 \\ Index Copernicus Value (2013): 6.14 | Impact Factor (2015): 6.391}

such as hypertension, diabetes mellitus, seizure disorders, bronchial asthma, patients on drugs known to have antiemetic effect(Phenothiazide, Scopolamine, Tricyclic Antidepressants) were excluded from the study.

Pre-anaesthetic assessment included medical/surgical history, general/systemic examination, airway examination and investigations, such as complete haemogram, bleeding time and clotting time, chest x-ray and in addition fasting blood sugar, and electrocardiogram for patients more than 35 years of age.

Peripheral venous cannulation using $20 \mathrm{G}$ cannula was done on dorsum of hand. Monitors including Blood pressure, cardioscope, pulse oximeter were attached to patient. Baseline haemodynamics like pulse, blood pressure, oxygen saturation and respiratory rate were noted. All patients were premedicated with Injection Glycopyrrolate 0.004 $\mathrm{mg} / \mathrm{kg}$ intravenously, Injection Midazolam $0.02 \mathrm{mg} / \mathrm{kg}$ intravenously and Injection Fentanyl $2 \mu \mathrm{g} / \mathrm{kg}$ intravenously.

The patients were allocated, by computer-generated random numbers, into two groups. The random allocation sequence was concealed in sealed opaque envelopes until a group was assigned. Group $\mathrm{G}(\mathrm{n}=30)$ received injection Granisetron $40 \mu \mathrm{g} / \mathrm{kg}$ intravenously, Group D $(\mathrm{n}=30)$ received injection Dexamethasone $160 \mu \mathrm{g} / \mathrm{kg}$ intravenously .

The study drug was administered just before the induction of Anaesthesia. General anaesthesia was administered with injection Thiopentone sodium $3-5 \mathrm{mg} / \mathrm{kg}$ intravenously. After confirming ventilation, tracheal intubation was facilitated with injection succinylcholine $1-2 \mathrm{mg} / \mathrm{kg}$ intravenously. Intermittent positive pressure ventilation was performed using low airway pressure to avoid gastric distension. A nasogastric tube and urinary bladder catheter were inserted in all patients. Diclofenac suppository $100 \mathrm{mg}$ per rectum for post operative analgesia was inserted in all patients. Surgical ports were infiltrated with $0.25 \%$ injection bupivacaine not exceeding dose of $2 \mathrm{mg} / \mathrm{kg}$.

After tracheal intubation, anaesthesia was maintained with $70 \%$ nitrous oxide in oxygen along with isoflurane. Muscle relaxation was provided with injection vecuronium $0.08 \mathrm{mg} / \mathrm{kg}$ intravenously. During surgery, patients were placed in Trendelenburg's position and abdomen was insufflated with carbondioxide. During laparoscopy, intraabdominal pressure was maintained at $1.3-1.8 \mathrm{kPa}(10-12$ $\mathrm{mm}$ of $\mathrm{Hg}$ ) by a carbon dioxide insufflator.

Patients were monitored during anaesthesia by continuous ECG, blood pressure, pulse oximetry and capnometry. At the completion of surgery, patients were made supine, residual pneumoperitoneum removed. Stomach emptied with nasogastric tube suction before reversal of anaesthesia. After respiratory attempts residual neuromuscular blockade was antagonized with injection Neostigmine $0.05 \mathrm{mg} / \mathrm{kg}$ and injection Glycopyrrolate $0.008 \mathrm{mg} / \mathrm{kg}$ intravenously and patients were extubated after having adequate tone, power and verbal response. All patients received IV fluids to starvation and maintenance fluid $(4 \mathrm{ml} / \mathrm{kg} / \mathrm{hr})$ was given. After surgery, patients were observed for 24 hours.
All patients were shifted to recovery room, and were monitored for patients' hemodynamics, pulse rate, blood pressure, oxygen saturation. Postoperatively, injection diclofenac $75 \mathrm{mg}$ IM was given to patients who requested for analgesia.

Nausea and vomiting was assessed by direct questioning of the patient at 0 hour, 1 hour, 2 hours, 4 hours and 24 hours after recovery from anaesthesia with the help of three-point ordinal scale of nausea and vomiting score $[3,4,10,11]$.

$0=$ no emetic symptoms

$1=$ nausea

$2=$ vomiting

The efficacy of study medication was assessed in terms of number of emetic episode, percentage of emesis free patients, percentage of nausea free patients for $24 \mathrm{hrs}$. post operatively.

Rescue antiemetic injection metoclopromide $200 \mu \mathrm{g} / \mathrm{kg}$ was given to patients who had nausea for 30 mins or more than one emetic episode in 15 minutes or patients who had two or more episodes of vomiting during first $24 \mathrm{hrs}$ after anaesthesia. Side effects like itching, headache, dizziness, constipation, myalgia were also noted.

\section{Statistical Analysis}

All quantitative variables namely, blood pressure, pulse, $\mathrm{O}_{2}$ saturation, age, weight, duration of surgery were represented in terms of mean and standard deviation and compared using unpaired ' $t$ ' test. Comparison was done at 5\% level of significance. Paired t-test was used for comparison within the group. Chi-square test was used for non-parametric data, ('p' value $<0.05$ considered as statistically significant).

\section{Observation And Results}

Sixty healthy patients of ASA Grade I - II, between 18-60 years, undergoing any elective laparoscopic surgery were randomly distributed in two groups of 30 each. These patients were randomized in double-blind technique to receive $40 \mu \mathrm{g} / \mathrm{kg}$ injection Granisetron $(2 \mathrm{mg}$ ) in Group $\mathrm{G}$ and $160 \mu \mathrm{g} / \mathrm{kg}$ injection Dexamethasone $(8 \mathrm{mg})$ in Group D just before the induction of anaesthesia.

In this study, the treatment groups were similar with regards to age, weight, type of surgical procedure, duration of anaesthesia, anaesthetic drugs administered and postoperative analgesics. (Table 1)

Intra-operatively changes in pulse rate and blood pressure were noted. Comparison was done by applying unpaired ' $t$ ' test. No statistically significant difference was found in pulse rate as well as Systolic BP.(Table 2)

All the patients underwent elective laparoscopy surgery under balanced general anaesthesia and received adequate postoperative analgesia. In Group $\mathrm{G}$, in first 2 hours, four patients $(13.3 \%)$ had nausea and at 4 hours one patient $(3.3 \%)$ had nausea requiring rescue antiemetic. At 1 hour postoperatively, only one patient $(3.3 \%)$ had vomiting requiring rescue antiemetic. In next 4-24 hours, none patient 


\section{International Journal of Science and Research (IJSR) \\ ISSN (Online): 2319-7064}

Index Copernicus Value (2013): 6.14 | Impact Factor (2015): 6.391

had nausea or vomiting and not required rescue antiemetic.(Table 3a)

In group $\mathrm{D}$, two patients $(6.7 \%)$ at 1 hour and two patients $(6.7 \%)$ at 2 hour and one patient (3.3\%) 4 hour and three patients $(10 \%)$ at 24 hours postoperatively reported nausea requiring rescue antiemetic. At 2 hour and 24 hours two patients $(6.7 \%)$ and 6 patients $(20 \%)$ reported vomiting requiring rescue antiemetic respectively.(Table $3 \mathbf{b}$ )

Antiemetic effect of intravenous dexamethasone was comparable to granisetron. Total five patient of $30(16 \%)$ had nausea and one patient of 30 (3.3\%) had vomiting in granisetron group as compared to 5 patient of $30(16 \%)$ had nausea and two of $30(6.7 \%)$ patients had vomiting in dexamethasone group at first four hours postoperatively.

In 4 to 24 hours postoperatively granisetron proved to have superior antiemetic effect than dexamethasone in which 3 patient out of $30(10 \%)$ had nausea and 6 patients out of 30 (20\%) had vomiting as compared to none of the patient in granisetron group had nausea or vomiting. This was statistically significant $p$ value being less than 0.005 . (Table 4)

Four patients from group $\mathrm{G}$ required one rescue antiemetic and one patient required rescue antiemetic twice, whereas in Group D nine patients required rescue antiemetics once and two patients required rescue antiemetic twice. (Fig 1)

In group $\mathrm{G}$ mild headache was reported in $10.0 \%$ of patients and dizziness reported in $10 \%$ of patients and myalgia was reported in $3.3 \%$ of patients which were mild and no any treatment required for it. Adverse effects though not significant were observed in group G. in 24 hours post operatively.

\section{Discussion}

Postoperative nausea and vomiting (PONV) are among the most common complications after laparoscopic surgeries. [2] It is unpleasant distressing experience for patients resulting in significant morbidity, longer stay in recovery room. The reported incidence of nausea and vomiting after laparoscopic cholecystectomy varies from 53-72\%. [3]

The aetiology of PONV following laparoscopic surgeries includes the effect of intraperitoneal insufflated carbon dioxide on residual stretching and irritation of peritoneum. A number of factors, including age, sex, obesity, anaesthetic technique, duration of surgery duration of anaesthesia, analgesics used and postoperative pain are also considered to increase the incidence of PONV after general anaesthesia for elective surgery $[12,13,14]$

As the number of laparoscopic surgeries have increased with technical advance over the past few years, so is the search for finding effective antiemetic for decreasing the incidence of post-operative nausea and vomiting( PONY) Antiemetic drugs used currently (e.g. anticholinergics, dopamine receptor antagonists, and antihistaminics), although effective, possess clinically significant side effects (e.g. restlessness, dry mouth, tachycardia and extrapyramidal symptoms). [7] The $5 \mathrm{HT}_{3}$ receptor antagonists like granisetron, ondansetron are promising new agents in the treatment of postoperative nausea and vomiting because they are devoid of sedation, extrapyramidal reactions, or drug interactions with anaesthetic drugs. $[15,16]$

Granisetron is a selective antagonist of serotonin at the 5 HT3 receptors and acts at the area postrema and the nucleus tractus solitarius which contains a number of $5 \mathrm{HT}_{3}$ receptors. It also has a peripheral action at $5 \mathrm{HT}_{3}$ receptors in the small intestine. [17]. Granisetron is effective in the treatment of emesis in patients receiving cisplatin chemotherapy. [15]

Studies done by Yoshitaka F et al in 1994\& 1995 concluded that granisetron is superior to metoclopromide or droperidol in the prevention of postoperative nausea and vomiting after anaesthesia and $40 \mu \mathrm{g} / \mathrm{kg}$ is the appropriate dose. [10, 18]

In 1981, dexamethasone given orally and intravenously was reported to be effective in reducing incidence of emesis.[19] Dexamethasone is a glucocorticoid that produces a strong antiemetic effect by an undetermined mechanism. It may act through prostaglandin antagonism, serotonin inhibition in the gut, and the releasing endorphins. Liu and colleagues demonstrated that dexamethasone alone at doses of $5 \mathrm{mg}$ and $2.5 \mathrm{mg}$ are as effective as $10 \mathrm{mg}$ in reducing the incidence of PONV. [20] Recently dexamethasone has been found to have prophylactic effect on postoperative nausea $\&$ vomiting (PONV) in patients undergoing tonsillectomy, thyroidectomy \& abdominal hysterectomy. [9]

As more and more surgeries are being performed on the day care basis, there is a search for a single dose, effective antiemetic with fewer side effects than currently used antiemetic agents. There are no studies which include comparison of granisetron and dexamethasone alone.

We studied 60 healthy patients between 18 - 60 years, undergoing any elective laparoscopy surgery (associated with high incidence of PONV). All the patients underwent the similar preoperative fasting, premedication, standardized balanced opioid anaesthesia and postoperative analgesia. The main objective of our study was to compare efficacy with prophylactic single dose of granisetron $(40 \mu \mathrm{g} / \mathrm{kg}-2 \mathrm{mg})$ with single dose of dexamethasone $(160 \mu \mathrm{g} / \mathrm{kg}-8 \mathrm{~kg})$ in preventing postoperative nausea and vomiting over 24 hours postoperatively.

Control group with Placebo drug was not considered qwing to high incidence of PONY in laparoscopic surgeries. At each interval of time, pulse rate, blood pressure was measured in the two groups. There was no significant change in haemodynamics. The study drug was well tolerated by patients without any significant adverse effects.

In our study, in first four hours, five patients out of $30(5 / 30$ - $16 \%$ ) had nausea while one patient out of $30(1 / 30-3 \%)$ had vomiting in granisetron group. The incidence seen in first four hours in our study was comparable to incidence seen in studies done by Yoshitaka F. et al in 1994.In their study, one patient out of $20(5 \%)$ had vomiting after using granisetron $(3 \mathrm{mg})$. [10,11] In dexamethasone group, we

\section{Volume 5 Issue 7, July 2016 www.ijsr.net}




\section{International Journal of Science and Research (IJSR) \\ ISSN (Online): 2319-7064 \\ Index Copernicus Value (2013): 6.14 | Impact Factor (2015): 6.391}

found that five patients out of $30(5 / 30=16 \%)$ had nausea and two patients out of $30(2 / 30-6.7 \%)$ had vomiting in first four hours postoperatively. This incidence in our study was comparable to incidence found in studies done by J.J. Wang et al in 2000. They found that eight patients out of 41 $(8 / 41-20 \%)$ had nausea and three patients out of 41 had vomiting (3/41 - 7\%) in Dexamethasone(10mg) group in first four hours postoperatively. [3, 4] Thus the incidence of nausea and vomiting in both the groups was comparable in first four hours.

In 4 - 24 hours postoperatively, none of the patients in granisetron group had nausea or vomiting. This incidence was comparable to the study done by Yoshitaka F. et al in 1994 where only one patient out of 20 had nausea and none patient had vomiting in $3-24$ hours postoperatively. [10] The study done by Yoshitaka F. et al in 1995 again had similar results. [18]

In dexamethasone group, during 4-24 hours postoperatively, three out of 30 patients $(3 / 30-10 \%)$ had nausea and six out of 30 patients $(6 / 30-20 \%)$ had vomiting. In study done by J.J. Wang et al in 2000, five patients out of 41 had nausea $(5 / 41-12 \%)$ and two patients out of $41(2 / 41-5 \%)$ had vomiting in 4 - 24 hours postoperatively. Nasreen $\mathrm{L}$ et al in 2005 found that six patients out $50(6 / 50-12 \%)$ had nausea and two patients out of $50(2 / 50-4 \%)$ had vomiting in $4-10$ hours postoperatively. ${ }^{9}$

In 4 - 24 hours postoperatively, in our study, in Granisetron group, none of the patients had nausea or vomiting while in Dexamethasone group, three patients out of $50(3 / 30-10 \%)$ had nausea and six patients out of $30(6 / 30-20 \%)$ had vomiting. So in 4 - 24 hours, Granisetron is proved to be more effective than dexamethasone. Yoshitaka F. et al, in 1995, have found that many patients receiving granisetron had nausea and vomiting when used in dose of $20 \mu \mathrm{g} / \mathrm{kg}$.

In our study, in first four hours, six patients out of 30 (6/30 - 20\%) required rescue antimetic in granisedtron group and seven patients out of $30(7 / 30-23 \%)$ required rescue antiemetic in dexamethasone group. While in 4-24 hour study, no patient in granisetron group required rescue antiemetic while nine patients out of 30 (9/30 - 30\%) required rescue antiemetic in dexamethasone group $(\mathrm{P}<0.05)$. Thus granisetron is proved to be more effective than dexamethasone.

In granisetron group mild headache was noted in three patients $(10 \%)$ for which no treatment was required. Mild dizziness was noted in three patients $(10 \%)$ in granisetron group for which no treatment required. Myalgia was reported in one patient $(3 \%)$ which was mild in granisetron group. Itching or constipation were not reported in any of the patients in both groups. Excessive sedation, extrapyramidal symptoms, allergic reactions were not noted in any of this study group. No adverse effect was seen in dexamethasone group in 24 hours postoperatively.

In the study done by Yoshitaka F. et al in 1995 |two patients out of $25(8 \%)$ had headache in granisetron group,one patient (4\%) had dizziness and one patient (4\%)had drowsinessess which were comparable to side effects seen in our study. Dexamethasone had no adverse effects and granisetron had fewer adverse effects which were mild and no treatment required for it.

We conclude that, the single dose of $8 \mathrm{mg}$ of dexamethasone which is economical without any known adverse effects is equally effective as granisetron in its single optimal effective dose ie. $40 \mu \mathrm{g} / \mathrm{kg}(2 \mathrm{mg})$ in preventing postoperative nausea and vomiting in first 4 hours in patients undergoing laparoscopic surgeries. But in $4-24$ hours, granisetron is more effective with minimal adverse effect and will prove cost - effective as it will reduce the cost by decreasing unanticipated hospital admission and improving patient satisfaction.

\section{Conclusion}

Intravenous single dose granisetron in dosage $(40 \mu \mathrm{g} / \mathrm{kg}-2$ $\mathrm{mg}$ ) is preferred over single dose dexamethasone in preventing PONV in patients undergoing laparoscopic surgeries.

\section{References}

[1] Yuill G, Gwinnutt C: Postoperative nausea and vomiting. Update in Anaesthesia, World Anaesthesia Issue 17 (2003) Article 2.

[2] Gan T J, Meyer T, Apfel C C, Chung F, Davis P J, Eubanks $\mathrm{S}$ et al: Consensus Guidelines for managing postoperative Nausea and Vomiting; Anaesthesia Analgesia 2003; 97(1): 62-71.

[3] Wang J J, HoST, Liu Y H, Lee S C, Liu Y C,Liao Y C, Ho C M: Dexamethasone reduces nausea and vomiting after laparoscopic cholecystectomy. British Journal of Anaesthesia 1999; 83 (5): 772-5.

[4] Wang J. J.,Ho S. T., Liu H.S., Ho C.M.: Prophylactic antiemetic effect of dexamethasone in women undergoing ambulatory laparoscopic surgery. British Journal of Anaesthesia 2000; 84(4):459-62.

[5] Gan T J , Coop A, Philip B K: A Randomized DoubleBlind study of Granisetron plus Dexamethasoneversus ondansetron plus Dexamethasone to prevent postoperative nausea and vomiting in patients undergoing abdominal hysterectomy. Anaesthesia Analgesia 2005; 101:1323-9.

[6] Leeser J ,Lip H: Prevention of post operative nausea and vomiting using ondansetron - A new, selective, 5HT3 receptor antagonist. Anaesthesia Analgesia 1991; 72: $751-5$

[7] Rowbotham D.J. Current Management of postoperative nausea and vomiting. British Journal of Anaesthesia 1992; 69 (5) 46S-59S.

[8] D Russel, Kenny GNC. 5HT3 antagonist in postoperative nausea and vomiting British Journal of Anaesthesia 199269 (3): 63-68S.

[9] Laiq N, Khan M N, Qureshi F A, Khan S, Jan A S. Dexamethasone as antiemetic during gynaecological laparoscopic surgery. J Coll Physicians Surg Pak. 2005 Dec;15(12):778-81.

[10]Fujii Y, Tanaka H, Toyooka H. Reduction of postoperative nausea and vomiting with granisetron. Can J Anaesth 1994; 41: 291-4. 


\section{International Journal of Science and Research (IJSR) \\ ISSN (Online): 2319-7064 \\ Index Copernicus Value (2013): 6.14 | Impact Factor (2015): 6.391}

[11]Fujii Y, Tanaka H, Toyooka H. Optimal anti-emetic dose of granisetron for preventing postoperative nausea and vomiting. Can J Anaesth 1994; 41:794-7.

[12] Palazzo MGA, Strunin L. Anaesthesia and emesis- Part I. Etiology. Canadian Anaesthetist Society Journal 1984; 31: 178-187.

[13] Mehernoor. F. Watcha Paul F. White - Postoperative nausea and vomiting. Its etiology, treatment and prevention. Anaesthesiology 77:162-184, 1992.

[14] Rabey P G, Smith G. Anaesthetic factors contributing to post-operative nausea and vomiting. British Journal of Anaesthesia 1992; 69: 40S-45S.

[15] Yarker YE, McTavish D, Granisetron: an update of its therapeutic use in nausea and vomiting induced by antineoplastic therapy. Drugs 1994; 48: 761-93.

[16] Wilde M I, Markham A. Ondansetron: a review of its pharmacology and preliminary clinical findings in novel applications. Drugs 1996; 52: 773-94.
[17] Katsuya M, Yumiko T. The antimetic efficacy of prophylactic granisetron in gynaecologic surgery. Anaesthesia Analgesia 1995; 80: 970-4.

[18]Fujii Y, Tanaka H, Toyooka H. Prevention of postoperative nausea and vomiting with granisetron: a randomized, double-blind comparison with droperidol. Can J Anaesth 1995; 42: 852-6

[19] McKenzie R, Tantisira, Boonrak , Karambelkar, Deepa $\mathrm{J}$, Riley et al: Comparison of ondansetron with ondansetron plus dexamethasone in the prevention of postoperative nausea and vomiting. Anaesthesia Analgesia 1994; 79: 961-4.

[20]Elhakim M, Nafie M, Mahmoud K, Atef A Dexamethasone $8 \mathrm{mg}$ in combination with ondansetron $4 \mathrm{mg}$ appears to be the optimal dose for the prevention of nausea and vomiting after laparoscopic cholecystectomy. Canadian Journal of Anaesthesia 2002; 49(9): 922-926.

Table 1: Patient Demographic Data

\begin{tabular}{|c|c|c|c|}
\hline Variables & \multicolumn{3}{|c|}{ Groups (Mean \pm S.D. $)$} \\
\hline & $\begin{array}{c}\text { Group G } \\
(\mathrm{n}=30)\end{array}$ & $\begin{array}{c}\text { Group D } \\
(\mathrm{n}=30)\end{array}$ & P value \\
\hline Age (years) & $29.07 \pm 11.07$ & $28.90+7.72$ & 0.946 \\
\hline Weight $(\mathrm{kg})$ & $49.77 \pm 5.73$ & $50.10+5.35$ & 0.817 \\
\hline Duration of surgery $(\mathrm{min})$ & $92.67 \pm 18.97$ & $84.83+16.32$ & 0.092 \\
\hline $\begin{array}{c}\text { Intraoperative injection } \\
\text { fentanyl }(\mu \mathrm{gm})\end{array}$ & $112.60+32.83$ & $105.47+20.73$ & 0.319 \\
\hline
\end{tabular}

Table 2: Average Pulse Rate and Systolic Blood Pressure in Two Groups

\begin{tabular}{|l|l|l|l|l|l|l|}
\hline \multirow{2}{*}{ Time } & \multicolumn{3}{|c|}{ PULSE (per min) } & \multicolumn{3}{c|}{ SYSTOLIC BP (mm Hg) } \\
\cline { 2 - 7 } & Group G & Group D & P value & Group G & Group D & P value \\
\hline Preop & $83.87 \pm 7.99$ & $84.73 \pm 6.44$ & 0.646 & $118.00 \pm 11.26$ & $114.67 \pm 8.60$ & 0.203 \\
\hline Intraop & & & & & & \\
$1 / 2 \mathrm{hr}$ & $90.20 \pm 11.4$ & $93.33 \pm 7.07$ & 0.209 & $103.53 \pm 18.43$ & $99.80 \pm 13.77$ & 0.378 \\
$1 \mathrm{hr}$ & $80.67 \pm 8.84$ & $82.00 \pm 7.10$ & 0.522 & $101.80 \pm 12.74$ & $101.40 \pm 11.56$ & 0.899 \\
$11 / 2 \mathrm{hr}$ & $80.87 \pm 7.74$ & $80.53 \pm 5.53$ & 0.849 & $109.13 \pm 13.45$ & $104.67 \pm 10.10$ & 0.151 \\
$2 \mathrm{hr}$ & $82.64 \pm 8.33$ & $81.65 \pm 4.54$ & 0.662 & $114.09 \pm 12.21$ & $114.00 \pm 9.13$ & 0.980 \\
\hline Postop & & & & & & \\
Ohr & $83.60 \pm 6.77$ & $83.33 \pm 5.18$ & 0.865 & $114.27 \pm 9.39$ & $112.27 \pm 8.54$ & 0.392 \\
$1 \mathrm{hr}$ & $83.13 \pm 6.57$ & $84.07 \pm 4.50$ & 0.524 & $113.40 \pm 9.67$ & $112.67 \pm 7.54$ & 0.745 \\
$2 \mathrm{hr}$ & $83.60 \pm 7.99$ & $85.00 \pm 5.35$ & 0.428 & $116.20 \pm 8.73$ & $113.27 \pm 8.14$ & 0.184 \\
$4 \mathrm{hr}$ & $82.40 \pm 6.26$ & $83.07 \pm 4.22$ & 0.631 & $115.60 \pm 7.32$ & $113.33 \pm 7.05$ & 0.227 \\
$24 \mathrm{hr}$ & $82.47 \pm 6.38$ & $84.60 \pm 3.41$ & 0.112 & $115.47 \pm 7.62$ & $115.20 \pm 7.05$ & 0.889 \\
\hline
\end{tabular}

Table 3a: Three Point Ordinal Scale Of PONV in Group G

\begin{tabular}{|c|c|c|c|c|c|}
\hline Score of PONV & Ohr & $1 \mathrm{hr}$ & $2 \mathrm{hr}$ & $4 \mathrm{hr}$ & $24 \mathrm{hr}$ \\
\hline 0 & 30 & 29 & 26 & 29 & 30 \\
& $100.0 \%$ & $96.7 \%$ & $86.7 \%$ & $96.7 \%$ & $100.0 \%$ \\
\hline 1 & - & - & 4 & 1 & - \\
& & & $13.3 \%$ & $3.3 \%$ & \\
\hline 2 & - & 1 & - & - & - \\
& & $3.3 \%$ & & & \\
\hline
\end{tabular}

Table 3b: Three Point Ordinal Scale Of PONV in Group D

\begin{tabular}{|c|c|c|c|c|c|}
\hline Score of PONV & Ohr & $1 \mathrm{hr}$ & $2 \mathrm{hr}$ & $4 \mathrm{hr}$ & $24 \mathrm{hr}$ \\
\hline 0 & 30 & 28 & 26 & 29 & 21 \\
& $100.0 \%$ & $93.3 \%$ & $86.7 \%$ & $96.7 \%$ & $70.0 \%$ \\
\hline 1 & - & 2 & 2 & 1 & 3 \\
& & $6.7 \%$ & $6.7 \%$ & $3.3 \%$ & $10.0 \%$ \\
\hline 2 & - & - & 2 & - & 6 \\
& & & $6.7 \%$ & & $20.0 \%$ \\
\hline
\end{tabular}

Volume 5 Issue 7, July 2016 www.ijsr.net

Licensed Under Creative Commons Attribution CC BY 
International Journal of Science and Research (IJSR)

ISSN (Online): 2319-7064

Index Copernicus Value (2013): 6.14 | Impact Factor (2015): 6.391

Table 4: Percentage of PONV in 24 hours in two groups

\begin{tabular}{|c|c|c|c|c|c|}
\hline Time (Hours) & \multicolumn{2}{|c|}{ Group G } & \multicolumn{2}{c|}{ Group D } & P' Value \\
\hline & No. & $\mathbf{\%}$ & No. & $\mathbf{\%}$ & \\
\hline O hour & 0 & 0 & 0 & 0 & 0 \\
\hline 1 hour & 1 & $3.3 \%$ & 2 & $6.7 \%$ & 0.221 \\
\hline 2 hour & 4 & $13.3 \%$ & 4 & $13.3 \%$ & 0.264 \\
\hline 4 hour & 1 & $3.3 \%$ & 1 & $3.3 \%$ & 1.00 \\
\hline 24 hour & 0 & 0 & 9 & $30.0 \%$ & $0.005^{*}$ \\
\hline
\end{tabular}

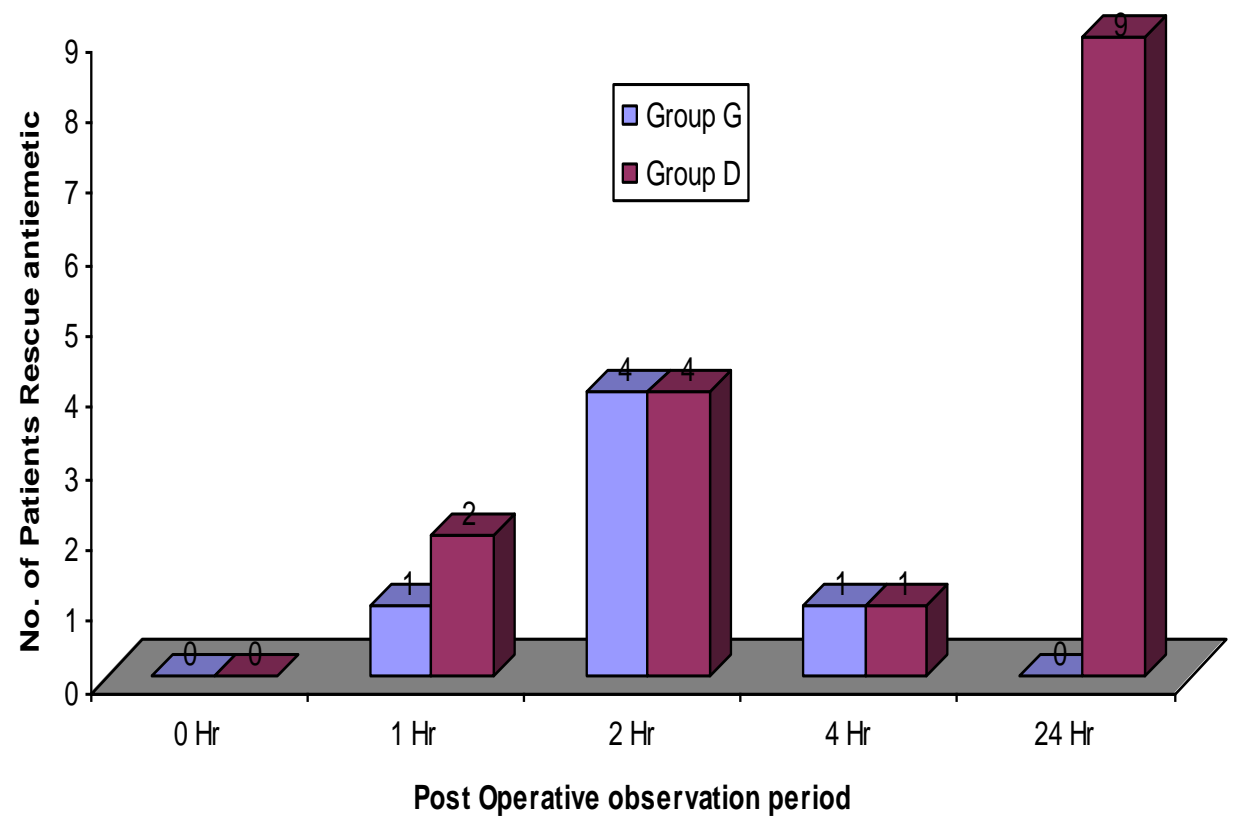

Figure 1: No of Patients requiring anti-emetic in 24 hours

Volume 5 Issue 7, July 2016 www.ijsr.net

Licensed Under Creative Commons Attribution CC BY 